\title{
MULTIPLE-FIELD INTERSTITIAL PHOTODYNAMIC THERAPY OF SUBCUTANEOUSLY TRANSPLANTED CHOLANGIOCELLULAR CARCINOMA RS-1 IN RATS
}

\author{
D.A. Tzerkovsky* \\ N.N. Alexandrov National Cancer Center of Belarus, Lesnoy 223040, Republic of Belarus
}

\begin{abstract}
The aim of present study was to investigate an antitumor efficacy of multiple-field interstitial photodynamic therapy (iPDT) in vivo. Materials and Methods: The study was performed on 15 white random-bred rats with subcutaneously transplanted cholangiocellular carcinoma RS-1. Chlorine-based photosensitizer (PS) Ce6CPPPS was administered via single injection at a dose of $2.5 \mathrm{mg} / \mathrm{kg}$ into the animal's caudal vein. Photoirradiation (PI) of tumors was carried out $3 \mathrm{~h}$ after PS administration using 7 optical fibers SMA-905 with diode laser with $660 \pm 5 \mathrm{~nm}$ wavelength at exposure doses of 150 and $300 \mathrm{~J} / \mathrm{cm}^{2}$ with $0.21 \mathrm{~W} / \mathrm{cm}^{2}$ fluency rate. The total power density was $360 \mathrm{~mW}$ and treatment time was 12 and $24 \mathrm{~min}$. Antitumor efficacy of iPDT was assessed by evaluation of necrosis areas and depth of necrosis in experimental tumors. Results: The results have shown that interstitial PI with multi-field low power density enhanced the antitumor effect of PDT in the RS-1 model. Necrosis areas in tumor tissues after PI with exposure doses $150 \mathrm{and} 300 \mathrm{~J} / \mathrm{cm}^{2} 24 \mathrm{~h}$ and $96 \mathrm{~h}$ after treatment were $83.78 \pm 4.25$ and $100 \%(p=0.00074) ; 56.79 \pm 3.24$ and $95.46 \pm 1.64 \%(p<0.00001)$, respectively. Conclusion: An analysis of the literature data and the results obtained in this study evidence on high effectiveness of the method of multiple-field. Key Words: multiple-field interstitial photodynamic therapy, photosensitizer, cholangiocellular carcinoma.
\end{abstract}

Photodynamic therapy (PDT) is a modern and highly effective option in the treatment of malignant tumors of the skin, lung, bladder, brain, pancreas and other localizations [1-3]. PDT is a treatment method based on the significant increase of the cytotoxicity of drugs with photoirradiation (PI) of the tumor tissue. According to numerous studies, photochemical reactions include a direct interaction of excited molecules with the help of PI, photosensitizer (PS) on the substrate and forming transient radicals that react with oxygen. Interaction initiates a complexcascade of free radicals, such as singlet oxygen $\left({ }^{1} \mathrm{O}_{2}\right)$, hydroxyl radical $(\mathrm{OH})$, hydrogen peroxide $\left(\mathrm{H}_{2} \mathrm{O}_{2}\right)$ and superoxide anion radical $\left(\mathrm{O}_{2}^{-}\right)$, causing the development of oxidative stress syndrome. As a result, PDT effectively induces tumor-cell apoptosis and necrosis (Necr). The two possible mechanisms might be: a) promoting mitochondria to release cytochrome $C$ and activate caspase-3, then to initiate apoptosis; b) destroying microvessels, inhibition of angiogenesis and the induction of ischemia and anoxia of tumor cells, resulting in ischemic Necr $[2,4,5]$.

PDT has rarely been used clinically in the treatment of liver tumors, mainly because of effective accumulation of PS in liver tissue [6, 7]. Distribution studies show that PS are accumulated in high amounts in reticuloendothelial tissue, such as liver, spleen, and kidney, and in particular, liver tissue contains high PS levels after its administration $[8,9]$. Therefore, superficial tumor PI causes substantial liver Necr. The limited light penetration during superficial illumination makes it impossible to treat deep-seated or larger solid tumors. In order to prevent possible complications, research teams recommended the use of an interstitial type of PI of liver tumors.

Submitted: March 03, 2017.

*Correspondence: E-mail: tzerkovsky@mail.ru Abbreviations used: IPDT - interstitial photodynamic therapy; $\mathrm{mTH}-$ PC - meta-tetra(hydroxyphenyl)chlorine; Necr - necrosis; PDT photodynamic therapy; $\mathrm{PI}$ - photoirradiation; PS - photosensitizer.
The ability of interstitial photodynamic therapy (iPDT) to cause a destruction of liver tumors has been demonstrated in in vitro [10-12] and in vivo [13-15] studies, using hematoporphyrin, photofrin, meta-tetra(hydroxyphenyl) chlorine (mTHPC) and other photosensitizing agents.

In the present study, we investigated the effects of Ce6CPPPS-mediated PDT using multi-field interstitial PI on subcutaneously transplanted cholangiocellular carcinoma RS-1 in rats.

\section{MATERIALS AND METHODS}

Experimental animals. The study was conducted on 15 white randomly bred rats of both sexes $(220 \pm 40 \mathrm{~g})$ obtained from the vivarium of N.N. Alexandrov National Cancer Center of Belarus. The animals received a standard diet and had permanent access to water. All manipulations were carried out according to Methodic instructions for carrying out preclinical investigations of the pharmacokinetics of pharmacologic substances and drugs presented in the "Good Laboratory Practice TKP 125-2008" (Health Ministry of Republic Belarus, Minsk). Animal experiments were performed according to the Rules of Ethic Committee. Before treatment, animals were anesthetized by intramuscular introduction of a solution of droperidol $(5.0 \mathrm{mg} / \mathrm{kg})$ and fentanil $(0.05 \mathrm{mg} / \mathrm{kg})$.

Experimental tumor model. As experimental tumor model, we used rat cholangiocellular carcinoma RS-1. RS-1 induced in rats with acetylaminefluorene in 1956 was identified as hepatocholangioma and was maintained by subcutaneous transplantation [16]. Before the treatment, the animals were anesthetized and immobilized. For experiments, tumor homogenate was implanted subcutaneously into the left inguinal area by the injection of $0.5 \mathrm{ml}$ of $20 \%$ tumor cells suspension in $0.6 \%$ Hank's solution. The experiments were performed 39-40 days after tumor implantation with tumor diameter reaching $40-50 \mathrm{~mm}$. 
Photosensitizer. Chlorin e6 conjugated with polyvinyl pyrrolidone (Ce6CPPPS) produced by Scientific Pharmaceutical Center of RUE "Belmedpreparaty", Minsk, Republic of Belarus) was injected into the tail vein at a standard dose of $2.5 \mathrm{mg} / \mathrm{kg}$.

Interstitial photodynamic therapy. PI of tumors was carried out $3 \mathrm{~h}$ after PS administration using diode laser with $660 \pm 5 \mathrm{~nm}$ wavelength ("PDT Diode laser", Minsk, Republic Belarus) at exposure doses of 150 and $300 \mathrm{~J} / \mathrm{cm}^{2}$ with $0.21 \mathrm{~W} / \mathrm{cm}^{2}$ fluency rate. The total power density was $360 \mathrm{~mW}$ and treatment time was 12 and $24 \mathrm{~min}$. 7 optical fibers SMA-905 ("Fotonika Plus", Ukraine) for PI were introduced into the tumor at a distance of $1 \mathrm{~cm}$ from each other at a depth of $1-1.5 \mathrm{~cm}$ (Fig. 1).

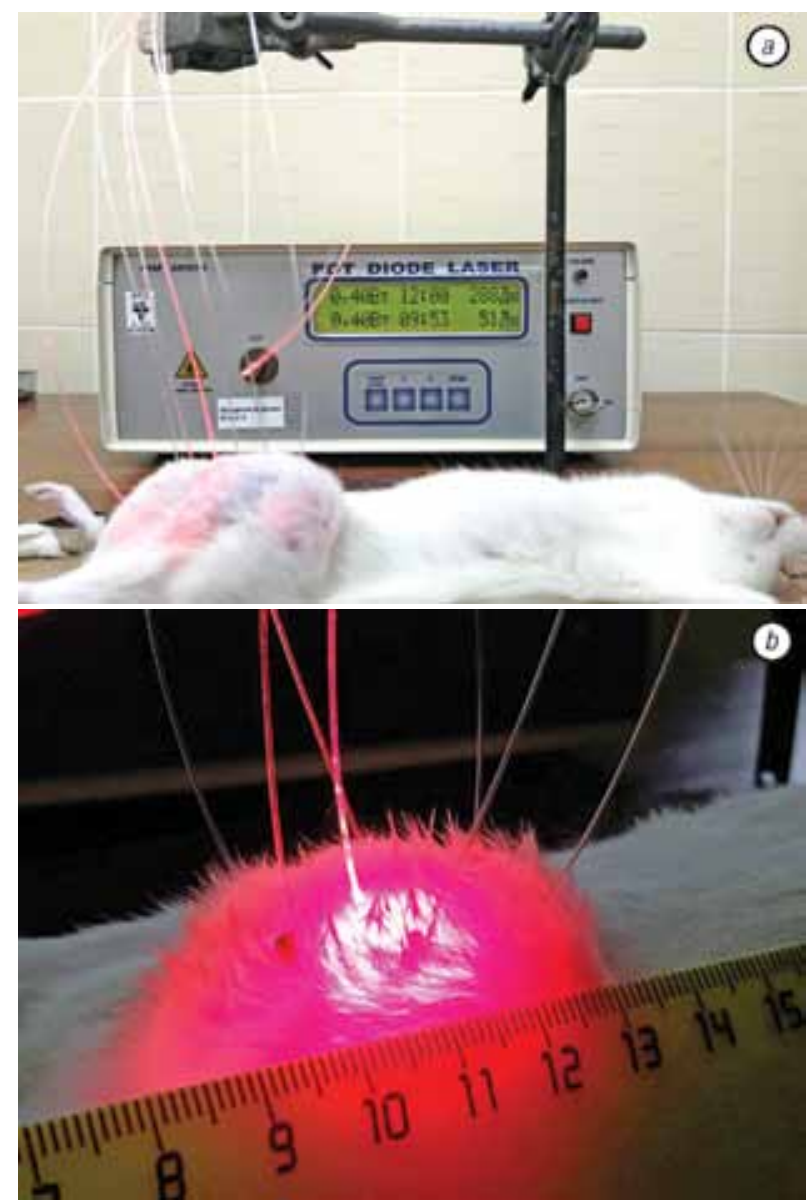

Fig. 1. Multiple-field iPDT: $a$ - photo-irradiation session; $b-$ subcutaneously transplanted tumor during the photo-irradiation session

The distribution of the total power density for each fiber is shown in Table 1 and Fig. 2.

Table 1. Distribution of the total power density $(P=360 \mathrm{~mW})$ to optical fibers

\begin{tabular}{lccccccc}
\hline \multicolumn{1}{c}{ Optical fiber No. } & 1 & 2 & 3 & 4 & 5 & 6 & 7 \\
\hline Power density, mW & 43.2 & 36.0 & 50.4 & 99.4 & 43.2 & 42.4 & 45.4 \\
Power density, \% & 12.0 & 10.0 & 14.0 & 27.6 & 12.0 & 11.8 & 12.6 \\
\hline
\end{tabular}

Antitumor efficacy was evaluated 24 and $96 \mathrm{~h}$ after the treatment by quantification of RS-1 tumor necrosis area (NecrA) by vital staining of tumor bearing animals with $0.6 \%$ Evans blue solution. The animals were sacrificed by chloroform; the tumors were removed, fixed in $10 \%$ formalin solution and frozen. Transverse tumor sections 2-3 mm thick were made. NecrA due to direct effect on tumor cells or structural and functional

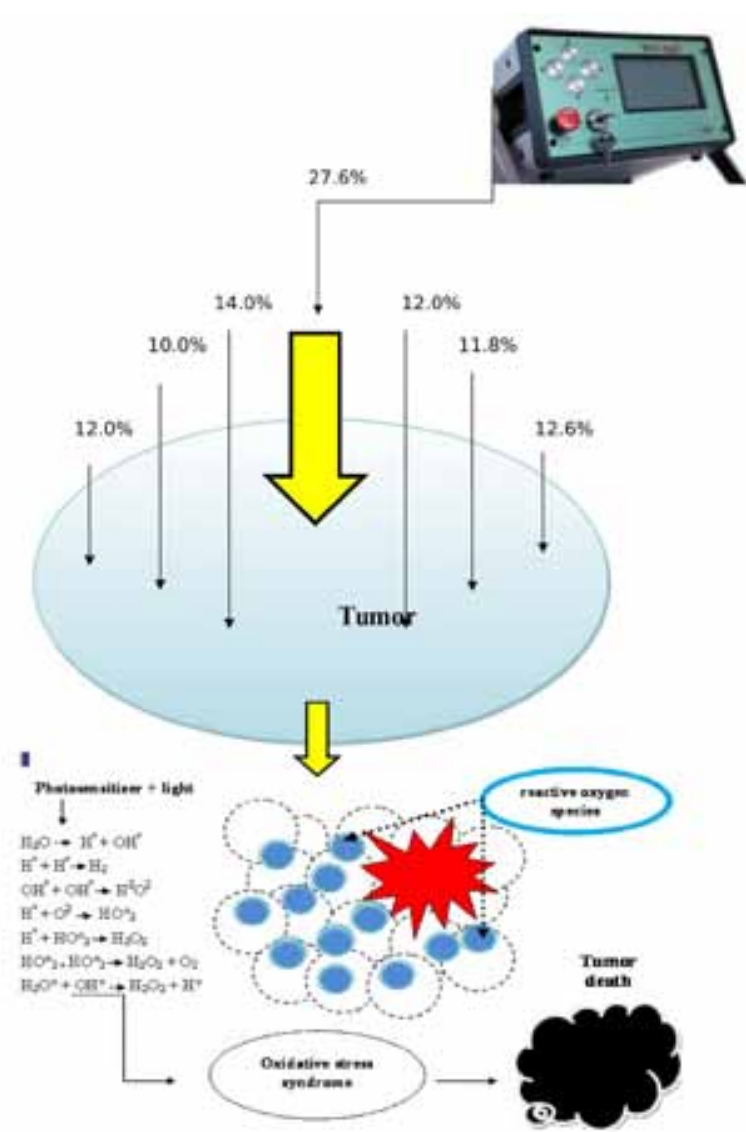

Fig. 2. Scheme of fibers location in the tumor and tumor cell death mechanism

disorders in microcirculation remained unstained. The percentage of tumor necrotic unstained parts was evaluated using "ImageJ" (NIH, Bethesda, USA).

Statistical processing of the results. The values obtained were processed using standard statistical methods of Origin Stat 7.0 software. Statistical significance of differences was relevant at $p<0.05$.

\section{RESULTS}

Early post-treatment changes. In the study, the sensitivity of subcutaneously implanted RS-1 to iPDT was investigated. According to our findings, all animals subjected to iPDT at an exposure dose $300 \mathrm{~J} / \mathrm{cm}^{2}$ presented the necrotic changes of maximal size (100\%). In the control group, this index showing the emergence of spontaneous central Necr was insignificant (14.88 \pm 4.33\%). Post-treatment necrotic changes after iPDT were assessed using the vital staining technique with Evans blue. Fig. 3 shows the data on NecrA in histotopographic sections of RS- 1 in untreated control and $24 \mathrm{~h}$ after iPDT at the exposure doses of 150 and $300 \mathrm{~J} / \mathrm{cm}^{2}$.

Fig. 4 shows the data on NecrA in histotopographic sections of RS- 1 in untreated control and $96 \mathrm{~h}$ after iPDT at the exposure doses of 150 and $300 \mathrm{~J} / \mathrm{cm}^{2}$.

Percentage of Necr in groups of animals treated with iPDT at the exposure doses of 150 and $300 \mathrm{~J} / \mathrm{cm}^{2} 24$ and $96 \mathrm{~h}$ after treatment is shown in Table 2.

Depth of tumor Necr in groups of animals treated with iPDT at exposure doses of 150 and $300 \mathrm{~J} / \mathrm{cm}^{2} 24$ and $96 \mathrm{~h}$ after treatment is shown in Table 3. 
Table 2. NecrA in histotopographic sections of subcutaneously transplanted RS-1 tumor of rats after treatment

\begin{tabular}{|c|c|c|c|c|c|}
\hline Groups & Number of sections, $n$ & Mean tumors area ${ }^{\#}(\mathrm{Sc}), \mathrm{cm}^{2}$ & $p$ & Mean $\mathrm{NecrA}^{\&}(\mathrm{SH}), \%$ & $p$ \\
\hline Control & & $11.78 \pm 1.12$ & & $14.88 \pm 4.33$ & \\
\hline & 16 & {$[\min =6.33 ; \max =14.32]$} & - & {$[\min =4,43 ; \max =20,25]$} & - \\
\hline $\mathrm{iPDT}^{\star} 150 \mathrm{~J} / \mathrm{cm}^{2}$ & 16 & $\begin{array}{c}13.57 \pm 0.94 \\
{[\min =9.33 ; \max =20.81]}\end{array}$ & 0.23 & $\begin{array}{c}83.78 \pm 4.25 \\
{[\min =53.46 ; \max =100]}\end{array}$ & $<0.00001$ \\
\hline iPDT $^{*} 300 \mathrm{~J} / \mathrm{cm}^{2}$ & 14 & $\begin{aligned} & 9,74 \pm 0,53 \\
{[\min =} & 5.39 ; \max =11.33]\end{aligned}$ & 0.11 & {$\left[\begin{array}{c}100 \\
{[\min =100 ; \max =100]}\end{array}\right.$} & $<0.00001$ \\
\hline iPDT $^{\star \star *} 150 \mathrm{~J} / \mathrm{cm}^{2}$ & 15 & $9.53 \pm 0.71$ & 010 & $56.79 \pm 3.24$ & $<0 \cap \cap \cap \cap 01$ \\
\hline $\mathrm{iPDT}^{\star \star} 300 \mathrm{~J} / \mathrm{cm}^{2}$ & 15 & $\begin{aligned} {[\min =} & 5.81 ; \max =13.61] \\
& 13.43 \pm 1.32 \\
{[\min =} & 6.98 ; \max =22.39]\end{aligned}$ & 0.35 & $\begin{array}{c}{[\min =36.00 ; \max =83.63]} \\
95.46 \pm 1.64 \\
{[\min =81.79 ; \max =100]}\end{array}$ & $<0.00001$ \\
\hline
\end{tabular}

Note: Tables 2 and $3:{ }^{*}$ NecrA in the tumor was evaluated $24 \mathrm{~h}$ after iPDT. ** NecrA in the tumor was evaluated $96 \mathrm{~h}$ after iPDT. ${ }^{*} S c$ iPDT $150 \mathrm{~J} / \mathrm{cm}^{2} 24 \mathrm{~h} v s$ Sc iPDT $150 \mathrm{~J} / \mathrm{cm}^{2} 96 \mathrm{~h}, p=0.0018$; Sc iPDT $300 \mathrm{~J} / \mathrm{cm}^{2} 24 \mathrm{~h}$ vs Sc iPDT $300 \mathrm{~J} / \mathrm{cm}^{2} 96 \mathrm{~h}, p=0.0015$; Sc iPDT $150 \mathrm{~J} / \mathrm{cm}^{2} 24 \mathrm{~h}$ vs Sc iPDT $300 \mathrm{~J} / \mathrm{cm}^{2} 24 \mathrm{~h}, p=$ 0.0013 ; Sc iPDT $150 \mathrm{~J} / \mathrm{cm}^{2} 96 \mathrm{~h}$ vs Sc iPDT $300 \mathrm{~J} / \mathrm{cm}^{2} 96 \mathrm{~h}, p=0.015$. ${ }^{8} \mathrm{SH}$ iPDT $150 \mathrm{~J} / \mathrm{cm}^{2} 24 \mathrm{~h}$ vs SH iPDT $150 \mathrm{~J} / \mathrm{cm}^{2} 96 \mathrm{~h}, p=0.00002 ;$ SH iPDT $300 \mathrm{~J} / \mathrm{cm}^{2} 24 \mathrm{~h}$ vs Sн iPDT $300 \mathrm{~J} / \mathrm{cm}^{2} 96 \mathrm{~h}, p=0.01$; Sн iPDT $150 \mathrm{~J} / \mathrm{cm}^{2} 24 \mathrm{~h}$ vs Sн iPDT $300 \mathrm{~J} / \mathrm{cm}^{2} 24 \mathrm{~h}, p=0.00074$; Sн iPDT $150 \mathrm{~J} / \mathrm{cm}^{2} 96 \mathrm{~h}$ vs Sн iPDT $300 \mathrm{~J} / \mathrm{cm}^{2} 96 \mathrm{~h}, p<0.00001$.

Table 3. Depth of Necr in histotopographic sections of subcutaneously transplanted RS-1 tumor of rats after treatment

\begin{tabular}{|c|c|c|c|}
\hline Groups & $\begin{array}{c}\text { Number } \\
\text { of sections, } n\end{array}$ & $\begin{array}{l}\text { Depth of tumor } \\
\mathrm{Necr}^{*}(\mathrm{~L}), \mathrm{cm}\end{array}$ & Mean NecrA (Sн), \% \\
\hline Control & 16 & $x_{1}-1$ & $\begin{array}{c}14.88 \pm 4.33 \\
{[\min =4.43 ; \max =20}\end{array}$ \\
\hline $\mathrm{iPDT}^{\star} 150 \mathrm{~J} / \mathrm{cm}^{2}$ & 16 & $2.69 \pm 0.16$ & $\begin{array}{r}83.78= \\
{[\min =53.46}\end{array}$ \\
\hline $\mathrm{iPDT}^{\star} 300 \mathrm{~J} / \mathrm{cm}^{2}$ & 14 & $2.39 \pm 0.11$ & $\begin{array}{c}100 \\
{[\min =100 ; \max =100]}\end{array}$ \\
\hline iPDT ${ }^{\star \star} 150 \mathrm{~J} / \mathrm{cm}^{2}$ & 15 & $2.15 \pm 0.11$ & $\begin{array}{c}56.79 \pm 3.24 \\
{[\min =36.00 ; \max =83.63}\end{array}$ \\
\hline $\mathrm{iPDT}^{\star \star} 300 \mathrm{~J} / \mathrm{cm}^{2}$ & 15 & $2.84 \pm 0.15$ & $\begin{array}{c}95.46 \pm 1.64 \\
{[\min =81.79 ; \max =100]}\end{array}$ \\
\hline
\end{tabular}

Note: "L iPDT $150 \mathrm{~J} / \mathrm{cm}^{2} 24 \mathrm{~h}$ vs L iPDT $150 \mathrm{~J} / \mathrm{cm}^{2} 96 \mathrm{~h}, p=0.009 ; \mathrm{L}$ iPDT $300 \mathrm{~J} / \mathrm{cm}^{2} 24 \mathrm{~h}$ vs L IPDT $300 \mathrm{~J} / \mathrm{cm}^{2} 96 \mathrm{~h}, p=0.022$.

The results obtained suggest that iPDT with multi-field low power density PI enhances the effect on the RS- 1 rats tumor model. The use of exposure dose of $300 \mathrm{~J} / \mathrm{cm}^{2} \mathrm{sig}$ nificantly increases NecrA in tumor tissues compared with $150 \mathrm{~J} / \mathrm{cm}^{2} 24 \mathrm{~h}(p=0.00074)$ and $96 \mathrm{~h}(p<0.00001)$.

\section{DISCUSSION}

Malignant primary and metastatic liver tumors are a serious problem for modern oncology. The main treatment for this type of tumors is surgical removal and chemotherapy. In spite of obvious achievements of the medical science of the last decades, the results of treatment of patients with liver tumors remain disappointing. With poor prognosis, development of new therapeutic modalities is desirable, especially for patients with nonresectable, non-transplantable, or recurrent liver tumors. Local tumor ablation therapies such as radiofrequency ablation, ethanol injection, cryotherapy, and PDT are potentially useful palliative approaches. IPDT is an effective and promising method of treatment of liver tumors.
At the moment, we found only a few articles, confirming the effectiveness of iPDT in the treatment of primary and metastatic liver tumors in laboratory animals $[13,14]$. Experimental studies, using hematoporphyrin derivative and photofrin, have shown iPDT to be capable of inducing tumor destruction within the liver, despite limitations like non-selective uptake and limited light penetration [13]. van Hillegersberg etal. [13] reported about high antitumor efficacy of iPDT ( $\lambda=625 \mathrm{~nm} ; 200 \mathrm{~mW} / \mathrm{cm}^{2} ; 100-1600 \mathrm{~J}$ ) with intravenously administered photofrin at a dose of $5 \mathrm{mg} / \mathrm{kg}$ in the treatment of colon carcinoma CC531, implanted in liver of Wag/Rij rats. The NecrA in the tumor and surrounding normal liver tissues depended on the absorbed dose of $\mathrm{PI}$ and increased with its increase $(p<0.001)$. The authors noted that application of an exposure dose of $800 \mathrm{~J}$ allows to achieve complete regression of tumors in $66.7 \%$ of animals. The authors have proved the fact that the use of iPDT allows achieving a good therapeutic results with a minimal risk of damage to normal liver tissues. Rovers et al. [14] performed iPDT $(\lambda=652 \mathrm{~nm}, 0.1 \mathrm{~W}, 15 \mathrm{~J})$ with intravenously administered of $\mathrm{mTHPC}$ at a dose $0.3 \mathrm{mg} / \mathrm{kg}$ of body weight on Wag/Rij rats with metastatic liver orthotopic model CC531 colon adenocarcinoma. Authors reported that iPDT resulted in complete tumor remission in $87 \%$ of animals [14].

van Duijnhoven et al. [17] investigated effects of iPDT $\left(\lambda=652 \mathrm{~nm}, 200 \mathrm{~mW}, 16 \mathrm{~J} / \mathrm{cm}^{2}\right)$ with $\mathrm{mTHPC}(0.3 \mathrm{mg} / \mathrm{kg})$ on liver metastases of orthotopic model of CC531 colon adenocarcinoma. Authors reported that iPDT was effective in causing photodynamically-induced photochemical Necr of tumors, but it did not affect the growth rate of nonilluminated tumors in the liver. Immunological staining
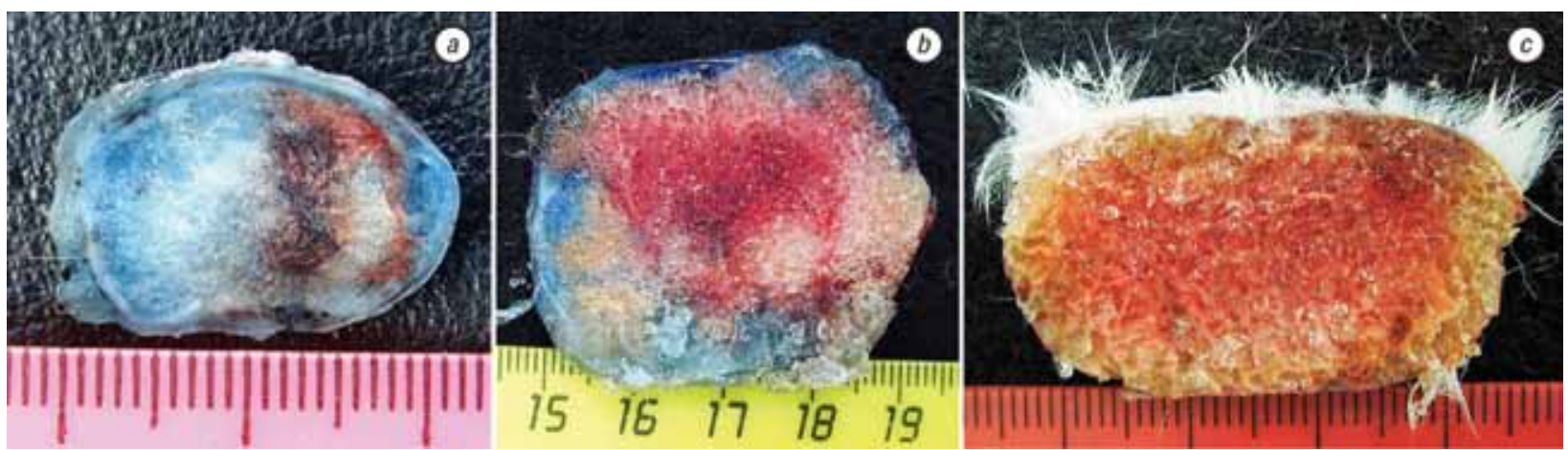

Fig. 3. Histotopographic sections of subcutaneously transplanted rats cholangiocellular carcinoma RS-1 in control group (a); $24 \mathrm{~h}$ after iPDT at the exposure doses of $150 \mathrm{~J} / \mathrm{cm}^{2}(b)$ and $300 \mathrm{~J} / \mathrm{cm}^{2}(c)$ (blue - viable tumor tissue, red - photochemical Necr) 


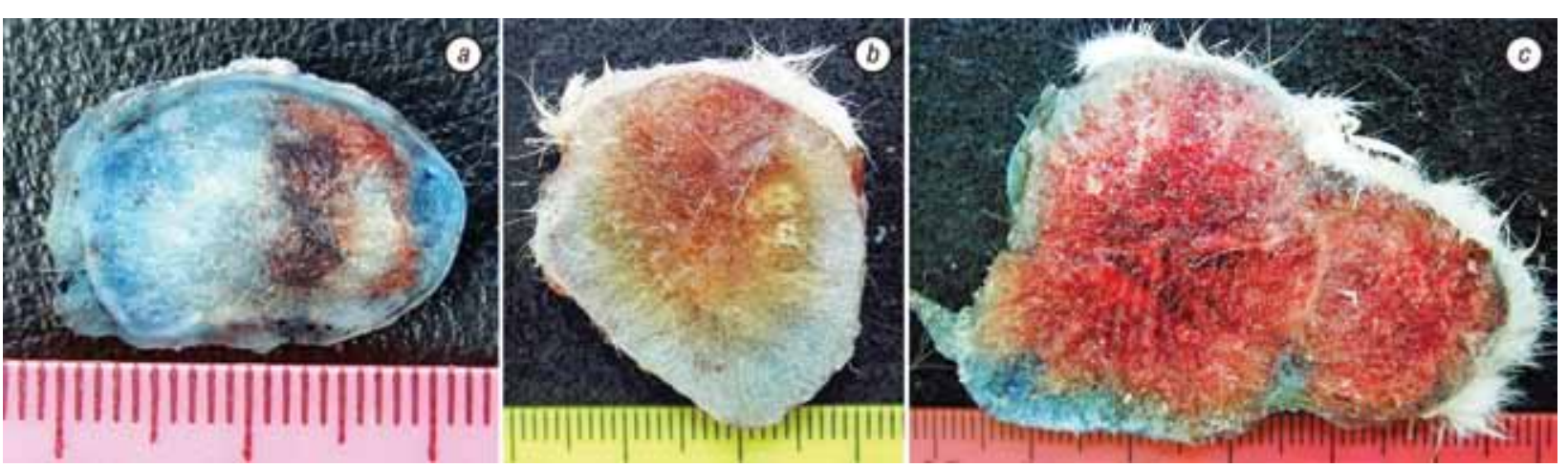

Fig. 4. Histotopographic sections of subcutaneously transplanted rats cholangiocellular carcinoma RS-1 in control group (a); $96 \mathrm{~h}$ after iPDT at the exposure doses of $150 \mathrm{~J} / \mathrm{cm}^{2}(b)$ and $300 \mathrm{~J} / \mathrm{cm}^{2}(c)$ (blue - viable tumor tissue, red - photochemical Necr)

of tumors showed natural killer cells to be significantly lower in tumors treated with interstitial PI than in control tumors $(p<0.05)$. Otake et al. [15] published the results of their study on the efficacy of iPDT $(\lambda=630 \mathrm{~nm}, 160 \mathrm{~mW}$, $47-90 \mathrm{~J} / \mathrm{cm}^{2}$ ) with 5 -ALA at a dose of $500 \mathrm{mg} / \mathrm{kg}$ administered intravenously $3 \mathrm{~h}$ before $\mathrm{Pl}$ in the treatment of chemically induced hepatocellular carcinoma in rats. The authors concluded that in all treated tumors, Necr was evident at $24 \mathrm{~h}$ after 5ALA-iPDT [15]. Several teams of scientists made successful attempts for the clinical testing of iPDT for patients with unresectable primary and metastatic malignant liver tumors [6, 7]. Vogl et al. [7] presented the results of several phase I clinical trials based on the use of iPDT in the treatment of the liver metastases. In the first study authors reported about 5 patients with liver metastasis of colorectal cancer treated with PS SQN 400 (mTHPBC) at a dose of $6 \mathrm{mg} / \mathrm{kg}$ and $\mathrm{PI}(\lambda=740 \mathrm{~nm}$; $60 \mathrm{~J} / \mathrm{cm}^{2}$ ) 120 h after SQN 400 administration. Depending on the location and size of lesions, the authors have used from 4 to 7 special fibers installed in the tumor site under the center CT control. After 3 months in all cases CT study recorded photodynamically-induced Necr with no evidence of damage to the normal liver parenchyma, and after 6 month in $50 \%$ of the metastase continued growth was not revealed [7]. In the second study, the authors have included 4 patients with liver metastasis of colorectal cancer $(n=3)$ and melanoma $(n=1)$. PS LS 11 (Talaporfin sodium) was injected intravenously at a standard dose of $40.0 \mathrm{mg} / \mathrm{m}^{2}$. At $4 \mathrm{~h}$ post-injection, a tumor was photoirradiated with a "PDT laser" with $25 \mathrm{~mm}$ optical fibers $\left(\lambda=630 \mathrm{~nm} ; 400 \mathrm{~mW} / \mathrm{cm}^{2} ; 100 \mathrm{~J} / \mathrm{cm}^{2}\right)$. The average size of Necr, confirmed the results of CT studies, was $14 \mathrm{~mm}$. At the control observation after 6 weeks in 2 cases complete regression of tumor was recorded [7].

However, a moderate number of studies in this field points on the need for further research to determine antitumor efficacy of iPDT in the treatment of this pathology. In further experimental studies, we plan to study the antitumor efficacy of iPDT in the treatment of other tumor strains. If positive results will be obtained, we will be able to recommend the developed method for approbation in clinical oncology.

\section{REFERENCES}

1. Photodynamic therapy. Methods and protocols. Gomer CJ, ed. Totowa, NJ: Humana Press Inc, 2010. 296 p.
2. Photodynamic therapy: From theory to application. Abdel-Kader MH, ed. Berlin: Springer-Verlag, 2014. 332 p.

3. Resistance to photodynamic therapy in cancer. Rapozzi V, Jori G, eds. Cham, Switzerland: Springer International Publishing AG, 2015. 263 p.

4. Dougherty TJ, Gomer CJ, Henderson BW, et al. Photodynamic therapy. J Natl Cancer Inst 1998; 90: 889-905.

5. Castano AP, Mroz P, Hamblin MR. Photodynamic therapy and anti-tumor immunity. Nat Rev Cancer 2006; 6: 535-45.

6. Engelmann K, Mack MG, Eichler K, et al. Interstitial photodynamic laser therapy for liver metastases: first results of a clinical phase I study. Rofo 2003; 175: 682-7 (in German).

7. Vogl TJ, Eichler K, Mack MG, et al. Interstitial photodynamic laser therapy in interventional oncology. Eur Radiol 2004; 14: $1063-73$.

8. Bown SG, Tralau CJ, Smith PD, et al. Photodynamic therapy with porphyrin and phthalocyanine sensitisation: quantitative studies in normal rat liver. Br J Cancer 1986; 54: 43-52.

9. Wang JD, Shen J, Zhou XP, et al. Optimal treatment opportunity for mTHPC-mediated photodynamic therapy of liver cancer. Lasers Med Sci 2013; 28: 1541-8.

10. Date M, Fukuchi K, Namiki Y, et al. Therapeutic effect of photodynamic therapy using PAD-S31 and diode laser on human liver cancer cells. Liver Int 2004; 24: 142-8.

11. Li WT, Tsao HW, Chen YY, et al. A study on the photodynamic properties of chlorophyll derivatives using human hepatocellular carcinoma cells. Photochem Photobiol Sci 2007; 6: 1341-8.

12. Xia C, Wang Y, Chen W, et al. New hydrophilic/lipophilic tetra- $\alpha$-(4-carboxyphenoxy) phthalocyanine zinc-mediated photodynamic therapy inhibits the proliferation of human hepatocellular carcinoma Bel-7402 cells by triggering apoptosis and arresting cell cycle. Molecules 2011; 16: 1389-401.

13. van Hillegersberg R, Marijnissen JP, Kort WJ, et al. Interstitial photodynamic therapy in a rat liver metastasis model. Br J Cancer 1992; 66: 1005-14.

14. Rovers JP, Saarnak AE, Molina A, et al. Effective treatment of liver metastases with photodynamic therapy, using the second-generation photosensitizer meta-tetra(hydroxyphenyl) chlorine (mTHPC), in a rat model. Br J Cancer 1999; 81: 600-8.

15. Otake M, Nishiwaki M, Kobayashi Y, et al. Selective accumulation of ALA-induced PpIX and photodynamic effect in chemically induced hepatocellular carcinoma. Br J Cancer 2003; 89: 730-6.

16. Malugina LL. Transplantable alveolar mucous liver carcinoma in rats RS-1. Vopr Oncol 1958; 4: 600-4 (in Russian).

17. van Duijnhoven FH, Aalbers RI, Rovers JP, et al. Immunological aspects of photodynamic therapy of liver tumors in a rat model for colorectal cancer. Photochem Photobiol 2003; 78: $235-40$. 